\title{
Contamination/Decontamination Problem
}

National Cancer Institute

\section{Source}

National Cancer Institute. Contamination/Decontamination Problem. NCI Thesaurus. Code 663276.

Problem associated with the presence of any unexpected foreign substance found in a device, on its surface or in the package materials, which may affect performance or intended use of the device, or problem that compromise effective decontamination of the device. 